\title{
LA FILOSOFÍA DE LA LIBERACIÓN COMO FILOSOFÍA DEL PUEBLO. LA EXPERIENCIA DEL GRUPO ARGENTINO: LA LÍNEA KUSCH, CULLEN, SCANNONE*
}

Fecha de entrega 20171006

Fecha de evaluación 20171027

Fecha de aprobación 20171126

\begin{abstract}
Iván Ariel Fresia ${ }^{* *}$
\end{abstract}
\section{Resumen}

La filosofía latinoamericana de la liberación en sus orígenes consideró la importancia del pueblo, lo popular, la cultura y los pobres. Aun con discusiones y divergencias en el interior del movimiento -a raíz de las diferentes concepciones filosóficas y políticas- pueblo-clase, pueblonación y pueblo-sectores populares estuvo presente en la producción de muchos de sus autores.

Todos asumieron la cuestión del pueblo, pero ninguno apostó en denominar tal filosofía de la liberación como "filosofía del pueblo". Cuestión que no dudaron en asumir, en cambio, cuando la producción teológica latinoamericana producida en Argentina fue denominada como "teología del pueblo", primero despectivamente

* Texto leído en el "II Congreso Internacional Interdisciplinario de Pensamiento Crítico: pensar América en diálogo. 6. Jornadas del Pensamiento Rodolfo Kusch. Foro de pensamiento filosófico Colombia 2017". Bogotá, 11-14 de octubre de 2017. Artículo de reflexión. Citar como: Fresia, I. (2018). La filosofía de la liberación como filosofía del pueblo. La experiencia del grupo argentino: la línea Kusch, Cullen, Scannone. Cuadernos de Filosofia Latinoamericana, 39(118), 77-94. D0I: https://doi. org/10.15332/10.15332/s0120-8462.2018.0118.05

* Doctor en Historia, Universidad Nacional de Cuyo, posgraduado en Ciencias Sociales, FLACSO, Argentina. Buenos Aires. Correo electrónico: arielfresia@hotmail.com. 
y posteriormente como nombre propio y nota característica. Es más, Scannone incluso consideró que era adecuado nombrar como "éticocultural" a la corriente filosófica inspirada en la sabiduría popular por él representada, pero difícilmente hubiera admitido que se denominara su filosofía inculturada de la liberación como "del pueblo".

Palabras clave: filosofía de la liberación, religión, pueblo, sabiduría popular, filosofía del pueblo.

\section{Abstract}

The Latin American philosophy of liberation in its origins considered the importance of the people, the popular, the culture and the poor. Even with discussions and divergences within the movement - following the different philosophical and political conceptions - people-class, people-nation, people-popular sectors was present in the production of many of its authors.

All took the question of the people, but none bet on calling such a philosophy of liberation as "philosophy of the people." Question that they did not hesitate to assume, however, when the Latin American theological production produced in Argentina was denominated like "theology of the people", first contemptuously and later like own name and characteristic note. Moreover, Scannone even considered it appropriate to name as "cultural ethic" the philosophical current inspired by the popular wisdom he represented, but would hardly have admitted that his inculturated philosophy of liberation was called "of the people".

Keywords: Fhilosophy of liberation, religion, people, popular knowledge, fhilosophy of the people.

\section{Resumo}

A filosofia latino-americana da libertação em suas origens considerou a importância do povo, o popular, a cultura e os pobres. Inclusive com discussões e divergências no interior do movimento - por causa das 
diferentes concepções filosóficas e políticas - povo-classe, povo-nação e povo-setores populares esteve presente na produção de muitos de seus autores.

Todos assumiram a questão do povo, mas ninguém apostou em denominar tal filosofia de libertação como "filosofia do povo". Questão que não duvidaram em assumir, ao contrário, quando a produção teológica latino-americana feita na Argentina foi denominada como "teologia do povo", primeiro depreciativamente e posteriormente como nome próprio e nota característica. Scannone inclusive considerou que era adequado nomear como "ético-cultural" à corrente filosófica inspirada na sabedoria popular por ele representada, mas dificilmente houvesse admitido que se denominasse sua filosofia inculturada da libertação como "do povo".

Palavras-clave: filosofia da libertação, religião, povo, sabedoria popular, filosofia do povo.

\section{Introducción}

La filosofía latinoamericana de la liberación en sus orígenes consideró la importancia del pueblo, lo popular, la cultura y los pobres. Aun con discusiones y divergencias en el interior del movimiento (Casalla, 1975) -a raíz de las diferentes concepciones filosóficas y políticas- pueblo-clase, pueblo-nación y pueblo-sectores populares estuvo presente en la reflexión de muchos de sus autores. Sobre todo, se reflejó en la preferencia por el uso del pueblo en tensión dialéctica con el antipueblo (élite) en la que la experiencia histórica del peronismo y el carácter conflictivo de su formación histórica estuvo en la génesis del concepto. El libro inaugural del movimiento (Ardiles, 1973) y el inmediato posterior (Ardiles y Casalla, 1975) abordaron desde diversas perspectivas la temática en cuestión.

Quisiera detenerme particularmente en la vertiente argentina de la filosofía de la liberación representada por autores como Kusch, Cullen y Scannone para desarrollar una particular manera de hacer filosofía de la liberación a partir del pueblo. Para

* Texto lido no "II Congresso Internacional Interdisciplinar do Pensamento Crítico: pensar América em diálogo. 6. Jornadas do Pensamento Rodolfo Kusch. Foro de pensamento filosófico Colômbia 2017". Bogotá, 11-14 de outubro de 2017. Artigo de reflexão. 
ello, daré un breve rodeo sobre el pensamiento de Rodolfo Kusch y Carlos Cullen atinente al argumento. Especialmente en Kusch, referido a la lógica de la negación y la ritualidad propias de la religión popular y, de Cullen, su tematización de la racionalidad sapiencial y la ambigüedad de tal sabiduría. Finalmente, aportaré algunos aspectos de la propuesta de Scannone respecto de la concepción de pueblo y filosofía del y desde el pueblo.

\section{Pueblo en la corriente fundacional de la filosofía de la liberación}

Muchos de los filósofos argentinos de la generación fundadora, argumentaron sobre la cuestión del pueblo desde diversas perspectivas y posicionamientos políticos. En el manifiesto del grupo expresan que una de las coincidencias (la tercera) es explícitamente que "el filósofo debe hacerse interprete de la filosofía implícita del pueblo latinoamericano, interpretándola críticamente" (Ardiles, 1973, p. 271). Y en la cuarta coincidencia expresan: "que es en el pobre y oprimido ('en el pueblo', según otra expresión) en donde se manifiesta lo nuevo de la historia, que el filósofo ha de pensar y decir" (Ardiles, 1973, p. 272). Pero ninguno apostó por denominar tal filosofía de la liberación como "filosofía del pueblo". Casalla (1973) se refirió al filosofar propio de América como de "servicio" (histórico, político y especulativo) al "proceso de liberación del pueblo", porque este, el pueblo -como comunidad popularmente organizada- es el sujeto de tal filosofar. Porque el filósofo de la liberación y la filosofía realizan una clara opción preferencial por el sujeto pobre y por el sujeto comunitario pobre (el pueblo y los pueblos). El pueblo se constituye, a partir de la opción preferencial por el pobre, en sujeto comunitario de la filosofía (Casalla, 1973, pp. 51-52).

Cullen (1973) desarrollaría la idea del descubrimiento de la nación como un universal no imperial, a partir del cual se produciría la liberación de la filosofía de esa tal universalidad en la que el filosofó sería "fiel al pueblo en su lucha por devenir nación" y la filosofía se comprendería como aquella "filosofía, liberada por esta lucha (la de devenir nación) elaborada y apropiada por el pueblo" (Cullen, 1973, p. 104). Scannone (1973) afirmó que su propuesta teoría sería una "articulación reflexiva y crítica" de la sabiduría popular en la que el pueblo es el sujeto. Por lo que la filosofía es filosofía a partir de la sabiduría popular como "praxis de liberación en que está embarcado el pueblo latinoamericano” (Scannone, 1973, pp. 267-269). 
Cuestión que no dudaron en asumir los teólogos, en cambio, cuando la producción teológica latinoamericana producida en Argentina fue denominada como "teología del pueblo", primero despectivamente como "teología del pueblo subsumida bajo la orientación general de la teología de la liberación” (Segundo, 1975, p. 264) y posteriormente como nombre propio y nota característica de tal orientación. Para los teólogos de la liberación también se trataba de una opción preferencial por el pobre, por el pueblo pobre quien era, a su vez, sujeto comunitario de la religiosidad (sabiduría) popular y, por lo tanto, sujeto de la teología producida a partir de tal religiosidad.

En cambio, la iniciativa de clasificación de Cerutti Guldberg (2006) que asignó la denominación de "populismo" o "populista" a una de las corrientes filosóficas en Argentina, donde ubicaba a Kusch, Cullen y Casalla en la ambigüedad concreta y en la línea del populismo de la ambigüedad abstracta o analógica ubicaba los desarrollos teóricos de Scannone y Dussel (Cerutti, 2006, p. 330) Antes que recoger la aceptación de tal denominación, disparó un sinnúmero de críticas -especialmente por parte de Dussel- por las “simplificaciones" de Cerutti (Dussel, 1985). Ciertamente, ninguno adoptó el nombre de populista, o popular o del pueblo para denominar tal producción filosófica realizada por el grupo fundacional argentino. Y la clasificación no tuvo éxito en el concierto de pensadores latinoamericanos, a excepción de algunos que recogieron aquella formulación acríticamente (Beorlegui, 2010, p. 705). Así, en un momento político violento, la vertiente argentina de filosofía de la liberación asumió temáticas relacionadas con la cultura y la religión, menos conflictivas para el régimen militar que aquellas referidas a la liberación ${ }^{1}$.

Scannone (1999) consideró, en tanto, que era adecuado nombrar como "ético-cultural" a la corriente filosófica inspirada en la sabiduría popular por él representada y que abrevaba en la inspiración de Kusch y en los aportes de Cullen (Scannone, 1999, p. 338). Sin embargo, hace poco tiempo, en un texto - por error editorial seguramenteun autor citó el artículo de Scannone: "Filosofía de la liberación" que apareciera en La Civiltá Cattolica como "Filosofía del pueblo" -en la nota al pie número 14- reabre la cuestión (Whelan, 2015, p. 56). Si bien en el periodo fundacional no cabía el uso de la expresión (por cuestiones políticas, por supuesto), considero que Scannone

1 Testimonio de Juan Carlos Scannone en Universidad Nacional del Oeste (UNO), 23/09/2017. Comentó que después del "golpe" ya no hablaron públicamente de "liberación" y se suspendieron las reuniones de San Miguel. En cambio, se reunían en la habitación del P. Ferrara en Devoto a discutir la "fenomenología de la crisis moral" de Cullen. 
actualmente admitiría que su filosofía inculturada de la liberación se denominara como filosofía “del pueblo" y “desde el pueblo".

\section{Estar, lógica de la negación y ardid litúrgico}

En Kusch (1975a) encontramos una insistencia (obsesión) por el "estar” y el "estar siendo", pero también en su producción se encuentra la presencia del "juego" y del "símbolo". Desde la "lógica de la negación" Kusch mantiene la relación entre "estar" y "juego" sin resolución dialéctica, donde el "símbolo" aparece como pura ambigüedad. Porque el "símbolo" remite a un significado que a la vez se retira en el doble moviendo de ocultar y mostrar a la vez.

Con la negación abro la referencia a lo que está y que no afirmo, de lo cual no digo que es, sino que está (...). La negación conduce a lo que está, y, todo lo que es, resulta sumergido en el estar. (Kusch, 1975a, p. 76)

De tal forma que "estar", "juego" y "símbolo" interactúan remitiéndose mutuamente. Las reglas del juego brindan elementos para comprender la sapiencialidad del filosofar desde el pensamiento popular. La articulación que propone Kusch entre lo "sapiencial" como "astucia radicalizada", salta las reglas de juego para proponer otras reglas donde el "símbolo" se manifiesta en una liturgia, "lo sapiencial implica una forma de astucia radicalizada, y por eso una liturgia que solo puede justificarse mediante el pensar simbólico" (Kusch, 2000, p. 481).

Lo sapiencial y lo simbólico, instaura la astucia como liturgia. Precisamente porque lo sapiencial no es "cierta forma menor al filosofar" sino que, es un modo de pensamiento diferente que salta las reglas de juego del "cogito". Las nuevas reglas del juego pertenecen al "estar siendo" y no al "yo soy", y, por lo tanto, pasa del plano de la afirmación lógica del "ser" a la "lógica de la negación” como forma de regreso al "estar". Kusch insistía que "preguntar por un pensamiento popular, encubre la posibilidad de descubrir un pensamiento propio" (Kusch, 1976, p. 147).

De nuevo aparece la astucia (saltar las reglas de juego para establecer otras reglas) y establecerse en lo simbólica, recurriendo a un "ardid litúrgico": 
Desde este ángulo cabe revisar el estar-siendo. El siendo no indica una posibilidad de ser, sino la curvatura del mismo. (...) Se trata de un estar-siendo que en realidad está. El siendo se limita a una astucia ante la trascendencia, en tanto incurre en un ardid litúrgico, un opuesto ausente en un plano meramente lógico, para regresar al estar. (Kusch, 2000, p. 481)

Lo simbólico que recurre al ardid litúrgico es descripto por Kusch en varios textos, especialmente cuando describe el ritual de Eucaliptus, por ejemplo, por nombrar solo un caso:

Es lo importante en el caso de Eucaliptus porque la verdad se da recién detrás del camión. Esto hace al sentido de la teología popular en el caso de Eucaliptus. La negación de las cosas transforma al mundo en símbolos, y el requerimiento de verdad recién se satisface en el área de la plegaria, el cual por supuesto tiene que llenarse con el mundo perfectamente estructurado de los dioses. Esa teología popular es una forma de llenar con algún género de racionalización la pregunta abierta por la verdad. Torna, por eso mismo, también verdadera a la teología misma. Y hay algo más. La persistencia de un área de la plegaria hace que el camión se reduzca como objeto. Mejor dicho, hace que el área del objeto no sea nada más que algo incrustado en medio de una totalidad que es todo el rito. (...) Si así fuera el pensar en Eucaliptus estaría en un vector distinto, transversal y simétricamente opuesto, al que utilizamos en la gran ciudad. Predomina la elección de los dioses innombrables, o sea el área de la plegaria, sobre la relación sujeto-objeto, mientras que en la ciudad disminuye al mínimo lo primero, para incrementar la relación entre el yo, como sujeto, y el camión, como objeto. (Kusch, 1975a, p. 42)

El símbolo (como ambigüedad), la religión (como conciliación) y la liturgia (como astucia) ante la trascendencia, disuelve a la vez que constituye tanto al sujeto como a los objetos. Así por medio de la astucia establece el ámbito de la plegaria (no la razón ni de la técnica), del rito y la sapiencialidad.

Es un área no pensada e imposible de pensar. El silencio en suma y detrás del silencio quizá un símbolo: quizá los dedos de la divinidad, la misma que estuvo arrugando los cerros: una vida realmente en común, la mía, la del viejito y la de la puna, y todos en silencio. (Kusch, 1988, p. 12) 
Kusch -desde una lógica distinta (de la negación)- acuñó un lenguaje filosófico para comprender América. Por influencia tardía de lecturas de Ricoeur a raíz del encuentro con el grupo argentino de investigación sobre religiosidad popular liderado por Scannone, se insinúa ya una lectura hermenéutica del estar en conexión con una fenomenología de las religiones nativas (Kusch, 1987). Porque precisamente:

La negación de las cosas transforma al mundo en símbolos, y el requerimiento de la verdad recién se satisface en el área de la plegaria, el cual por supuesto tiene que llenarse con el mundo perfectamente estructurado de los dioses. (Kusch, 1975a, p. 42)

\section{Efectivamente:}

Aquí se constituye el sujeto a partir de lo tradicionalmente significante (lo cultural) y remedia su desconstitución con lo simbólico. Lo religioso haría entonces a la alteridad de lo absoluto y a la labilidad del sujeto. La religio concilia el sujeto como un elemento concurrente entre la oposición disolvente y lo absoluto. Ahí asoma el dios que no entra en la filosofía y que no es el dios causa sui. Pero que, además, nunca podría entrar en la filosofía porque finca en su alteridad su condición de absoluto. (Kusch, 1978, p. 258)

El rito y la plegaria operan como acontecimiento existencial, como mediación del Misterio y lo Santo. Las cosas, pues, no son lo que parecen. Así, el camión de Eucaliptus es más que un camión.

Es lo importante en el caso de Eucaliptus porque la verdad se da recién detrás del camión. Esto hace al sentido de la teología popular en el caso de Eucaliptus. La negación de las cosas transforma al mundo en símbolos, y el requerimiento de verdad recién se satisface en el área de la plegaria, el cual por supuesto tiene que llenarse con el mundo perfectamente estructurado de los dioses. (Kusch, 1975a, p. 42)

En las religiones nativas y el pensamiento popular -que le es propio- el hombre y los objetos, las deidades, el mundo y el camión, están inmersos en la totalidad de un horizonte sacralizado, "donde, por ejemplo, el uso de un arado depende de un 
ritual" (Kusch, 1975b, p. 216). Por eso, el equilibrio de los opuestos es instaurado en las instancias existenciales a través del ritual, porque la religión es expresión de la cultura del pueblo, y en cierta medida, también es expresión de resistencia cultural a través de los proyectos políticos.

En Kusch, la lógica de la negación, la simbolicidad y el ardid litúrgico son formas del pensamiento popular, la religación y el ritual, en la que:

Cabe ver si lo sapiencial es otro modo en cierta forma menor al filosofar. O más bien lo filosófico no será en realidad un modo de lo sapiencial, dentro de las reglas de juego puestas por la razón de un cogito que proporciona una constitución, pero que sin embargo no logra constituir al sujeto. (Kusch, 2000, p. 474)

Esta es la inspiración para pensar el logos sapiencial, lo simbólico y el nosotros "arraigado a la tierra", desde los datos antropológicos del trabajo de campo, de la cultura, de los mitos, la piedad popular y las formas de organización social y comunitaria del pueblo, que retomaran tanto Cullen como Scannone.

\section{Ambigüedad, alteridad y sabiduría popular}

Cullen que venía trabajando la diferencia entre "ser" y "estar" y estaba llegando a conclusiones parecidas a las de Kusch. Pero en contacto con él se vuelve su lector, interprete e interlocutor privilegiado. Desde un aparato conceptual hegeliano y husserliano -según los casos- (Cullen, 1984; Cullen, 1986a). Cullen formulará la filosofía inspirada en el pensamiento popular desde la categoría de sabiduría popular. Y comprendió la religión y el símbolo como formas de la conciencia del pueblo y de los pueblos a partir del arraigo al suelo: como "nosotros estamos" en la tierra.

Recurriendo a la crítica del concepto "patio de los objetos", que había sido formulado por Kusch a partir del trabajo de campo y trabajado profusamente en la escritura de sus obras (Kusch, 1986; p. 128; Kusch, 1976, pp. 146-150), Cullen propone una intencionalidad simbólica como forma propia de la racionalidad sapiencial:

La sabiduría popular se instala en la certeza de otra muerte, la de las cosas.

Es que en realidad los pueblos saben que no hay meras cosas ni meras 
instituciones. Ciertamente que esto no implica renunciar a la universalidad, que parece ser el gran mérito del pensamiento cósico. A lo que se renuncia es a la universalidad violenta y abstracta del "patio de los objetos". En realidad, se trata de la intencionalidad simbólica, verdadera forma de la conciencia-sabiade-los-pueblos. (Cullen, 1978, pp. 126-127)

De esa manera, efectuando una crítica al logos filosófico de la tradición occidental, que se instala en la universalidad abstracta, propone otra universalidad desde lo simbólico. A partir de allí, identificará la racionalidad sapiencial como aquella racionalidad propia de los pueblos de la tierra, especialmente del pueblo argentino y latinoamericano. Desde otra lógica, la de la sabiduría popular, caracterizada por la simbolicidad (ambigüedad) y la diferencia (unidad plural), la eticidad (alteridad) y la trascendencia (religiosidad popular) (Cullen, 1986a).

Cullen asume el desafío formulado por Kusch cuando afirmaba que la filosofía estaba en búsqueda de su sujeto:

El problema de América en materia de filosofía es saber quién es el sujeto del filosofar. Evidentemente el discurso filosófico tiene un solo sujeto y este será un sujeto cultural. Mejor dicho, la filosofía es el discurso de una cultura que encuentra su sujeto. (Kusch, 1976, p. 123)

Así, la experiencia fenomenológica de la sabiduría popular reclama la mediación ético-religiosa del "nosotros arraigado a la tierra" (Kusch, 1976, p. 110), nosotroscultura-pueblo, o un "nosotros estamos en la tierra" como sujeto del discurso filosófico (Cullen, 1986b). El núcleo irreductible de la experiencia del pueblo es el "estar", el "nosotros estamos" y la consecuente sabiduría popular, originaria y generada por esa experiencia de arraigo a la tierra.

Por lo que, en Cullen (1986a), la sapiencialidad es la racionalidad propia de la sabiduría de un pueblo (no del sujeto moderno, ego cogito), es decir, de un "nosotros que está" (como autoconciencia de pueblo). Como el núcleo ético-mítico de la cultura se mueve en el elemento del símbolo y, por lo mismo, en el horizonte de la sapiencialidad, el sujeto de esa cultura es el pueblo o los pueblos (Cullen, 1978). Es precisamente esa sabiduría popular la que se convierte en el horizonte de una filosofía del pueblo no 
definida como tal, aunque implícito en esa primera producción de la década de los 70 y principios de los 80 .

\section{Religión, sabiduría popular y filosofía inculturada como filosofía del pueblo}

Scannone entra en contacto con Kusch por intermedio de Cullen y la participación de aquel en el equipo argentino sobre religiosidad popular (testimonio personal de Carlos Cullen, en la Universidad Nacional del Oeste (UNO), 23/09/2017. En ese momento miembro del equipo argentino de filosofía de la religión). Aunque se mantengan las diferencias propias del aparato conceptual, en el poco tiempo que se frecuentan se percibe la influencia, a juzgar por el desarrollo posterior de su pensamiento. Scannone se nutre del mismo fondo del pensamiento de Kusch -aunque no como única fuente-. Por un lado, se percibe en la relación religión del pueblo, sabiduría popular y logos inculturado (Scannone, 1978); por otro lado, en la conceptualización del simbolismo religioso, sabiduría popular, logos de la gratuidad. Son asumidos desde los “intentos posontoteológicos” de acceso filosófico a la religión, en el que sitúa a Kusch (Scannone, 2001).

Por eso, Scannone hace una relectura situada de Kusch para realizar nuevos planteamientos teóricos de manera provisoria e inacabada en el marco de la interpretación global de su pensamiento todavía en desarrollo. Pues las interpretaciones sucesivas de Scannone alcanzan un grado de sistematización no definitiva de Kusch, al que relee continuamente en relación con otros autores y contextos, temas y problemáticas específicas (Scannone, 2010). Pero ciertamente, el último Scannone está operando un retorno al horizonte originario del estar como anterior al símbolo, de acuerdo con Kusch; pero releído desde Marion. Porque el estar fundaría la posibilidad de un logos sapiencial como filosofía primera a partir de lo más originario de la donación del ahí sin el ser (Marion, 2011, p. 268).

Sabemos que el camino del pensamiento de Scannone asume los aportes de Kusch sobre el "estar" y la "lógica de la negación" y tematiza un logos prereflexivo como mediación para una filosofía desde la sabiduría popular: "implica un "logos” o inteligencia prereflexiva del sentido del mundo, del hombre y de Dios, que puede cumplir para la inteligencia de la fe una función mediadora semejante a la que cumple una filosofía reflexivamente elaborada” (Scannone, 1979, p. 4). Así, el 
carácter simbólico de la sabiduría popular y del logos propio encuentra su arraigo en el símbolo y no en el concepto:

Su elemento no es el concepto, como en la ciencia y la filosofía, sino el símbolo (símbolos, mitos, ritos, narraciones...). No procede argumentado -como la filosofía-, sino imaginando, plasmando, narrando historias, viviendo costumbres, obrando ritos... Pero no por ello deja de tener su propia normatividad, aunque no se trata del orden estricto, metódico, autocontrolado, propio de la filosófica. Aún más, no carece de discernimiento crítico; pero es el del 'olfato', la prudencia y la experiencia de la vida: en cambio la crítica propia del pensar filosófico será autoconsciente, reflexiva y metódica. (Scannone, 1982, p. 318)

El logos de la sabiduría popular implica la mediación simbólica del acierto fundante en tanto saber sapiencial:

Precisamente en ese movimiento acontece el saber sapiencial como correlativo a la mediación simbólica, el cual, cuando es auténtico, es al mismo tiempo acertado, recto y verdadero. Para emplear la expresión de R. Kusch: así acontece el acierto fundante, que -como lo dice Cullen- es simultáneamente lúdico, ético y lógico. (Scannone, 1986, p. 389)

Aquel logos de la sabiduría popular asume la instancia de que en Kusch significa estar arrojado en la tierrac, por lo que el carácter de la situacionalidad lleva a pensar la analogicidad del pensar latinoamericano:

De ahí que la filosofía pueda pensar analógicamente esa universalidad situada, aunque deba encontrarla en otras dimensiones de la vida. (...) El lenguaje simbólico la deja aparecer al mismo tiempo en su universalidad y en su situacionalidad, siendo el correlato intencional del nosotros-pueblo en su saber sapiencial de la vida y de la muerte (...). (Scannone, 1985, p. 283)

Scannone ya había asumido aquella tarea en donde el sujeto de una tal filosofía era el "nosotros-pueblo", pero no denominó a aquel proyecto "filosofía del pueblo" sino "filosofía desde la sabiduría popular" o "inculturada” privilegiando la instancia de la religiosidad y de la cultura y solapando en la denominación la mención de "pueblo": 
Ello parece encerrar, a primera vista contradictoria, a saber, entre filosofía como ciencia y sabiduría popular; entre universalidad propia del filosofar y la peculiaridad histórico-cultural latinoamericana; entre la noción filosófica de 'punto de partida' y el arraigo histórico en una cultura; entre sujeto aparentemente obvio del filosofar y el de la sabiduría popular, que es un 'nosotros': el pueblo. (Scannone, 1990, p. 9)

Revaloriza la sabiduría popular y el logos filosófico, la cultura y la relación entre pueblo y los pueblos de la tierra, (incluido el pueblo de Dios), sobre todo el argentino y los pueblos latinoamericanos, entendidos como pueblo-nación, con una historia, una cultura y un proyecto histórico comunes. Sin embargo, en América Latina fueron (y son) los sectores populares los que guardan mejor la cultura y religiosidad propias del pueblo en su conjunto.

La categoría 'pueblo', categoría clave para la interpretación política, social, histórica y cultural de América Latina, deriva de la de 'mestizaje cultural', como el pueblo se deriva de su ethos cultural de un tal mestizaje, por el entrecruce de dialécticas. Por ello, sin negar los antagonismos en el seno del pueblo, esta categoría sirve para descubrir en la realidad la primacía ontológica de la fraternidad y la unidad nacional sobre la conflictividad, así como para iluminar el camino de la resolución de los conflictos en justicia, respetando así la dignidad de quien solo es 'Juan Pueblo', en el respeto de la dignidad personal y colectiva de todos. La estructura ontológica de la realidad así lo exige. (Scannone, 1990, p. 179)

Influyen notablemente la experiencia de los teólogos de la COEPAL y su concepción sobre la pastoral popular y el pueblo como sujeto histórico en contrapartida a otras perspectivas que consideraban el sujeto histórico como clase social.

En la relevancia otorgada al nosotros-pueblo, sin desmedro de la afirmación de las personas; en el rol preferencial de los pobres en el pueblo como sujeto histórico y en su cultura popular; en la comprensión de la cultura desde su núcleo ético-sapiencial y las mediaciones sociales que lo encarnan y que aquel trasciende; en la interpretación de la historia, la cultura y el auténtico proceso de liberación latinoamericanos, etcétera. (Scannone, 1990, p. 11) 
En el diálogo internacional en torno a la interpretación del grupo argentino de filosofía de la religión (del pueblo), Scannone insiste ante la incomprensión de la categoría por parte de los colegas europeos en que "pueblo" tiene dos sentidos: como sujeto cultural-nación y como los pobres y sin privilegios (cercano al concepto de clase): “ambos sentidos tienen una estrecha relación. En el estilo de vida del así llamado 'mestizaje cultural' hay muchos más elementos del estilo de vida de los pobres que de los privilegiados" (Scannone, 1984, p. 26). Por un lado, también se perciben los aportes de Kusch para una hermenéutica histórico cultural del núcleo ético-mítico de la cultura (Ricoeur, 1986), donde los pobres son los principales depositarios. Y, por otro lado, la sistematización de Cullen sobre sabiduría popular, ciencia y nosotros; y también de Casalla sobre el universal situado. Estos aportes terminan de conformar el núcleo de influencias en la configuración del pensamiento del grupo argentino de filosofía de la liberación en la línea Kusch, Cullen, Scannone sobre pueblo y popular, sabiduría y cultura populares, religiosidad y logos filosófico.

Nombrar como corriente del "éthos cultural” a la filosófica inspirada en la sabiduría popular representada por esta línea de pensamiento es más acertada que la mención de populista -con tono despectivo- a consideración del mismo Scannone (Fornet, 1992, p. 103). Pero también cabría identificar esta producción latinoamericana como filosofía del pueblo o desde el pueblo (genitivo objetivo y subjetivo, como le gusta insistir a Scannone). Pues el pueblo es el sujeto del filosofar, y los procesos de liberación tienen al pueblo (nosotros en el sentido de Cullen o comunidad organizada en la versión de Casalla) como sujeto principal de la acción transformadora y del pensamiento emancipador.

\section{A modo de cierre}

La filosofía latinoamericana de la liberación en Argentina, en sus orígenes, tematizó pueblo, lo popular, la cultura y los pobres. Aun con discusiones y divergencias en el interior del movimiento -a raíz de las diferentes concepciones filosóficas y políticasla vertiente argentina asumió la versión pueblo-nación y pueblo-sectores populares configurando características propias en el contexto del movimiento filosófico.

En el caso de Scannone, uno de los referentes fundacionales del movimiento, la filosofía de la liberación es una filosofía inculturada. Comprendido como una filosofía 
del pueblo (en la corriente de las filosofías latinoamericanas de la liberación) a partir del logos sapiencial, pensamiento situado y, análogamente, de alcance universal.

En sintonía con la cuestión de una teología popular a partir de la "religión indígena y popular" (Kusch) y su articulación con la religión y la teología católica, se produce la elaboración de Lucio Gera y la escuela argentina de una teología del pueblo. Análogamente a lo que plantea la producción teológica argentina, la filosofía inculturada desde la sabiduría popular cuyo sujeto es el nosotros-pueblo, podría, efectivamente, considerarse una filosofía del pueblo y desde el pueblo. Los teólogos argentinos no dudaron en asumir la expresión "teología del pueblo", aunque primeramente fuera un rótulo despectivo. Pero posteriormente fue asumido como nombre propio y nota característica de esa producción teológica en el contexto de las teologías de la liberación.

Scannone consideró adecuado nombrar como perspectiva "ético-cultural" a la corriente filosófica inspirada en la sabiduría popular por él representada. En aquel momento, difícilmente hubiera admitido que se denominara su filosofía inculturada de la liberación como filosofía "del pueblo". Filosofía del pueblo en sentido propio y no populista como le asignara despectivamente en su momento. Pero, en el contexto actual, considero que ese podría ser otro nombre de la vertiente "ético-cultural" de la filosofía de la liberación latinoamericanas producida por Scannone.

\section{Referencias}

Ardiles, O., et al. (Ed.). (1973). Hacia una filosofía de la liberación latinoamericana. Buenos Aires.

Ardiles, O., Casalla, M., et al. (1975). Cultura popular y filosofía de la liberación. Una perspectiva latinoamericana, Buenos Aires.

Beorlegui, C. (2010). Historia del pensamiento filosófico latinoamericano. Una búsqueda incesante de la identidad. Bilbao.

Casalla, M. (1973). Filosofía y cultura nacional en la situación latinoamericana actual. En O. Ardiles (Ed.). Hacia una filosofía de la liberación latinoamericana, (pp. 3852). Buenos Aires. 
Casalla, M. (1975). Algunas precisiones en torno al concepto de 'pueblo'. Cultura popular y filosofía de la liberación. Una perspectiva latinoamericana, (33-69). Buenos Aires.

Cerutti, H. (2006). Filosofía de la liberación latinoamericana. México.

Cullen, C. (1973). El descubrimiento de la Nación y la liberación de la filosofía. En O. Ardiles (Ed.). Hacia una filosofía de la liberación latinoamericana, (pp. 92-104). Buenos Aires.

Cullen, C. (1978). Fenomenología de la crisis moral. Sabiduría de la experiencia de los pueblos. Buenos Aires, San Antonio.

Cullen, C. (1984). Sabiduría popular y fenomenología. En J. C. Scannone (Ed.). Sabiduría popular, símbolo y filosofía. Diálogo internacional en torno de una interpretación latinoamericana, (pp. 27-43). Buenos Aires.

Cullen, C. (1986a). Fenomenología y sabiduría popular. En C. Cullen (Ed.). Reflexiones desde América, tomo II. Ciencia y sabiduría: el problema de la filosofía latinoamericana, (pp. 47-81). Rosario.

Cullen, C. (1986b). Sentido y función de la filosofía en la Argentina de hoy. En C. Cullen (Ed.). Reflexiones desde América, tomo II. Ciencia y sabiduría: el problema de la filosofía latinoamericana, (pp. 29-37). Rosario.

Dussel, E. (1985). Cultura latinoamericana y filosofía de la liberación. Cultura popular revolucionaria más allá del populismo y del dogmatismo. Latinoamérica. Anuario Estudios Latinoamericanos, (17), 77-127. México.

Fornet, R. (1992). Estudios de filosofía latinoamericana, México

Kusch, R. (1975). La negación en el pensamiento popular, Buenos Aires.

Kusch, R. (1975b). MariDos, reflexiones sobre la cultura, En O. Ardiles, y M. Casalla et al. (Ed.). Cultura popular y filosofía de la liberación. Una perspectiva latinoamericana, (202-2019). Buenos Aires.

Kusch, R. (1976). Geocultura del hombre americano. Buenos Aires. 
Kusch, R. (1978). El pensamiento popular desde el punto de vista filosófico (consideraciones sobre el método, los supuestos y los contenidos posibles). Stromata, 34(3-4), 232-262.

Kusch, R. (1986). América profunda, Buenos Aires.

Kusch, R. (1987). Las religiones nativas. (Edición post mortem de trabajos de Elizabeth Lanata de Kusch). Buenos Aires.

Kusch, R. (1988). Cuando se viaja desde Abra Pampa. Folleto editado por Salma Haidar, publicado por primera vez en San Salvador de Jujuy, el 25 de junio de 1988.

Kusch, R. (2000). Estar siendo. Obras completas. Tomo 3, (468-485). Rosario.

Marion, J. L. (2011). Reducción y donación. Investigaciones acerca de Husserl, Heidegger y la fenomenología. Buenos Aires.

Meza, G. (2016). El 'vivir nosotros' amerindio vs. 'decir nosotros' de la globalización. Cuadernos de Filosofía Latinoamericana, 37(114), 151-166.

Ricoeur, P. (1986). Finitud y culpabilidad. Madrid.

Ricouer, P. (2013). La hermenéutica y el método de la ciencia social. Cuadernos de Filosofía latinoamericana, 34(109), 57-70.

Pachón, D. (2015). Rafael Gutiérrez Girardot y José Luis Romero: historiografía e identidad latinoamericana. Cuadernos de Filosofía Latinoamericana, 36(112), 151-169.

Scannone, J. C. (1973). Trascendencia, praxis liberadora y lenguaje. Hacia una filosofía de la religión postmoderna y latinoamericana situada. En O. Ardiles (Ed.). Hacia una filosofía de la liberación latinoamericana, (pp. 245-269). Buenos Aires.

Scannone, J. C. (1978). Religión, lenguaje y sabiduría de los pueblos. Aportes filosóficos a la problemática. Stromata, 34, 27-42.

Scannone, J. C. (1979). Sabiduría popular y teología inculturada. Stromata 35, 3-18.

Scannone, J. C. (1982). Sabiduría, filosofía e inculturación. La contribución de la analogía en un filosofar desde la sabiduría popular latinoamericana. Stromata, $38,317-327$. 
Scannone, J. C. (Ed.). (1984). Sabiduría popular, símbolo y filosofía. Diálogo internacional en torno de una interpretación latinoamericana. Buenos Aires.

Scannone, J. C. (1985). Religión del pueblo, sabiduría popular y filosofía inculturada. 3. ${ }^{\circ}$ Congreso Internacional de Filosofía Latinoamericana. Actas, (pp. 275-291). Bogotá, Universidad Santo Tomás de Aquino.

Scannone, J. C. (1986). Reflexiones acerca de la mediación simbólica. Stromata, 42, 387-390.

Scannone, J. C. (1990). Nuevo punto de partida de la filosofía latinoamericana. Buenos Aires.

Scannone, J. C. (1999). Filosofía in prospettiva latino-americana. Rassegna di teología, 40, 325-352.

Scannone, J. C. (2001). Una filosofía inculturada en América Latina. El equipo jesuita latinoamericano. Revista Portuguesa de Filosofía, 57, 155-161.

Scannone, J. C. (2010). El 'estar-siendo' como acontecimiento originario: articulación del horizonte tridimensional de la filosofía latinoamericana. Análisis. Revista Colombiana de Humanidades - Rodolfo Kusch: filosofía y cultura en América Latina, (77), 153-162.

Segundo, J. L. (1975). Liberación de la teología. Buenos Aires.

Whelan, G. (2015). Theological method in Evangelii Gaudium. A dialogue with Bernard Lonergan and Robert Doran. Gregorianum, 96(1), 51-75. 